\title{
Frequent DAP kinase but not p14 or Apaf-1 hypermethylation in B-cell chronic lymphocytic leukemia
}

\author{
C. S. Chim · T. K. Fung $\cdot$ K. F. Wong • \\ J. S. Lau $\cdot$ R. Liang
}

Received: 17 April 2006/Accepted: 6 June 2006/Published online: 3 August 2006

(C) The Japan Society of Human Genetics and Springer-Verlag 2006

\begin{abstract}
Dysregulation of apoptosis, and thus the p14/DAP kinase/HDM2/p53/Apaf-1 pathway, is potentially important in carcinogenesis. Chronic lymphocytic leukemia (CLL), uncommon in the Chinese, is a disease characterized by impaired apoptosis, of the neoplastic lymphocytes. Hypermethylation of p14, DAP kinase and Apaf-1 was studied by methylationspecific polymerase chain reaction (MSP) with primers for methylated (M-MSP) and unmethylated (U-MSP) alleles in 50 diagnostic marrow samples from patients with CLL. Chinese CLL patients had an indolent course similar to Caucasians with median overall survival (OS) of 96 months, which was adversely affected by advanced Rai stage (projected 5-year OS $=72 \%$ and $39 \%$ for Rai $\leq 2$ and Rai $>2 ; P=0.01)$. DAP kinase was methylated in $18(36 \%)$ patients while p14 and Apaf-1 were completely unmethylated in all the primary CLL samples. There was no correlation between DAP kinase hypermethylation and age, sex, poor-risk karyotype, lymphocyte count and Rai stage at diagnosis. Projected OS for patients with and without DAP kinase hypermethylation were 59 and $57 \%$ $(P=0.91)$. DAP kinase, but not 14 and Apaf-1, of the
\end{abstract}

K. F. Wong

Department of Pathology, Queen Elizabeth Hospital,

Hong Kong, China

J. S. Lau

Department of Medicine, Queen Elizabeth Hospital,

Hong Kong, China

C. S. Chim $(\bowtie) \cdot$ T. K. Fung $\cdot$ R. Liang

University Department of Medicine, Queen Mary Hospital,

University of Hong Kong, Pokfulam Road, Hong Kong,

China

e-mail: jcschim@hku.hk
DAP kinase/p14/HDM2/p53/Apaf-1 pathway is frequently hypermethylated in CLL, but not of prognostic significance. Moreover Chinese patients with CLL share a similarly indolent clinical course, and this is the first comprehensive study on $p 14, D A P$ kinase and Apaf-1 hypermethylation in CLL.

Keywords DAP kinase $\cdot$ P14 $\cdot$ Apaf-1 $\cdot$ Methylation · CLL $\cdot$ Chinese

\section{Introduction}

B-cell chronic lymphocytic leukemia (CLL) is the most common leukemia in the Western hemisphere but not Asia. (Parker et al. 1997) For example, the age-adjusted incidence of CLL in the US in 2000 was $3.4 / 100,000$. On the other hand, the age-adjusted incidence of CLL in Hong Kong in 2000 was 0.45/ 100,000 as estimated from the Hong Kong Cancer Registry. Patients are usually elderly and presents with lymphocytosis, lymphadenopathy and hepatosplenomegaly. (Keating et al. 2003) It runs an indolent clinical course, but may be complicated by development of autoimmune disorders, marrow failure and Richter transformation.

Death associated protein kinase (DAP kinase) is a pro-apoptotic calcium/calmodulin-regulated serine/ threonine kinase with a multidomain structure that participates in a wide array of apoptotic systems initiated by IFN-, TNF-, activated Fas, and detachment from extracellular matrix. (Raveh et al. 2001) It counteracts oncogene-induced transformation by activating $p 53$ in a $p 19^{A R F}$-dependent manner, thereby providing an intrinsic p53-dependent apoptotic check- 
point that is turned on by oncogenes at the initial stages of transformation. (Raveh et al. 2001)

p14 ${ }^{A R F}$ (p19 $9^{A r f}$ in mice) is one of the two genes encoded by the INK4A/ARF locus at chromosome 9p21. (Sherr et al. 2001) Alternative first exons ( $1 \alpha$ and exon $1 \beta)$, under the control of different promoters, specify the $5^{\prime}$ ends of $\mathrm{p} 16^{\mathrm{INK} 4 \mathrm{~A}}$ and $\mathrm{p} 14^{\mathrm{ARF}}$ respectively. These alternative exons $(1 \alpha$ and $1 \beta)$ are spliced to the same splice acceptor site in exon 2 , which is translated in alternative reading frames. p14 physically associates with HDM2, a negative regulator of p53, and protects p53 from HDM2-mediated proteosomal degradation. HDM2 possesses E3 ubiquitin ligase activity, thereby promoting proteasomal degradation of p53. Binding of $\mathrm{p} 14^{\mathrm{ARF}}$ to HDM2 results in localization of HDM2 to the nucleolus, precluding its interaction with p53. (Sherr et al. 2001) Moreover, E3 ubiquitin ligase activity of HDM2 is also inhibited by binding of $\mathrm{p} 14^{\mathrm{ARF}}$. Therefore, $\mathrm{p} 14^{\mathrm{ARF}}$ is a tumor suppressor by virtue of its ability to stabilize cellular p53 protein.

During the multi-step process of carcinogenesis, the first step is usually activation of a cellular oncogene. However, an intrinsic tumor suppression mechanism is triggered to result in apoptosis of cells carrying activated oncogenes. (Lowe et al. 2004) In particular, DAP kinase is upregulated and render apoptosis of cells harboring an activated oncogene in a p14 and p53-dependent manner, thereby conferring intrinsic tumor suppression. (Raveh et al. 2001) Various molecules are involved in the upstream regulation of p53 (DAP kinase, p14 and HDM2), and apoptosis is effected downstream by activation of apaf-1 with formation of apoptosome. (Hengartner et al. 2000) However, while p53 is frequently inactivated in many forms of solid cancers, p53 mutation is infrequent in haematological cancers. (Peller et al. 2003) Therefore, abrogation of this intrinsic tumor suppression mechanism, i.e. DAP kinase/p14/HDM2/ p53/Apaf-1 apoptosis pathway is potentially important in CLL.

DNA methylation involves the addition of a methyl group to the carbon 5 position of the cytosine ring in the CpG dinucleotide. (Chim et al. 2002; Herman et al. 2003) In many cancers, the $\mathrm{CpG}$ islands of selected genes are aberrantly methylated (hypermethylated), resulting in transcriptional repression. Various genes have been shown to be frequently methylated in cancers and leukemias including CLL. (Chim et al. 2002, 2005a, 2006; Esteller et al. 2001) However, as study of isolated genes or random assortment of genes preclude interpretation of the role of methylation in a specific pathway, we conducted a comprehensive study of hypermethylation of the putative tumor suppressors in the DAP kinase/p14/HDM2/p53/Apaf-1 apoptosis pathway in CLL. p53 was not investigated as it does not harbor a $\mathrm{CpG}$ island in promoter region (Accession number: J04238).

\section{Materials and method}

Patient, diagnosis and treatment

Diagnosis of CLL were made according to standard criteria, (Muller-Hermelink et al. 2001; Wong et al. 1999) which is based on classical morphology, low level of expression of light-chain-restricted surface immunoglobulin, and dual positivity of CD5 and CD23 in the neoplastic lymphocytes by flow cytometry. (Muller-Hermelink et al. 2001; Wong et al. 1999) Patients were staged according to Rai staging system. There were 40 males $(80 \%)$ and 10 females $(20 \%)$ with a median age of 65.5 years (range: 37-91 years). There were $11(22 \%)$ stage $0,12(24 \%)$ stage I, six $(12 \%)$ stage II, 11 (22\%) stage III and 10 (20\%) stage IV patients by Rai staging system respectively. The median presenting lymphocyte count was $17 \times 10^{9} / \mathrm{L}$ (range: $10-236 \times 10^{9} / \mathrm{L}$ ) There was variable infiltration of bone marrow by leukemic CLL cells ranging from $37 \%$ to $90 \%$, (median : 65\%) Patients received treatment if there were B symptoms, symptomatic organomegaly, extreme lymphocytosis, immune cytopenia, or rapid rise in lymphocyte count. Treatment included prednisolone, fludarabine or chlorambucil, or combination chemotherapy such as COPP (cyclophosphamide, vincristine, prednisolone and procarbazine), CVP (cyclophosphamide, vincristine and prednisolone) or FND (fludarabine, mitoxantrone and dexamethasone). (Ma et al. 2004) Cytogenetic data were available in 39 patients. (Wong et al. 1999) Previous studies showed that trisomy 12 in CLL is associated with atypical morphology, progressive disease and poor survival, whereas del(13q) appears to indicate a good prognosis. (Juliusson et al. 1998) Therefore, on this study, poor-risk cytogenetic aberrations was defined as those with trisomy 12 and complex abnormalities, and standard-risk cytogenetic aberration included those with normal karyotype and isolated deletion of 13q14. Poor risk cytogenetic changes (trisomy 12 and complex karyotypes) were found in 16/39 (41.0\%). Moreover, we have reported an adverse prognostic impact of poor-risk karyotype (such as trisomy 12 and complex aberrations) on overall survival, OS for patients with poor and standard risk karyotype were 84.5 and $32.2 \%$ $(P=0.03)$. (Chim et al. 2005a) 
Methylation-specific polymerase chain reaction (MSP)

High molecular weight genomic DNA was isolated by standard protocols from leukocytes of diagnostic bone marrow aspirates of 50 Chinese CLL patients, eight normal bone marrow donors in addition to DNA from peripheral blood of 12 healthy blood donors to the Hong Kong Red Cross Association.(Chim et al. 2004a) The methylation-specific polymerase chain reaction (MSP) for gene promoter methylation was performed as previously described. (Chim et al. 2004a) The primers for the methylated (M-MSP) and unmethylated (U-MSP) promoters of $p 14$, and DAP kinase were shown in Table 1. (Estellet et al. 2000; Chan et al. 2002) DNA from normal bone marrow and peripheral blood leukocytes was used as negative control, while methylated control DNA (CpGenome Universal Methylated DNA, Intergen) was used as positive control in all the experiments.

Statistical analysis

Correlation between $D A P$ kinase methylation status with continuous (mean age, mean diagnostic haemoglobin, lymphocyte and platelet counts) and categorical variables (sex, Rai staging and poor-risk cytogenetics) were studied by Student $t$ test and Chi-square test (or Fisher Exact test) respectively. Overall survival (OS) is measured from the date of diagnosis to the date of last follow-up or death. OS of patients with limited Rai stage (stages 0 , I and II) were compared to those with advanced stage (stage III and IV). Survival is plotted by the Kaplan-Meier method and compared by the log-rank test. All $P$ values were two-sided.

\section{Results}

MSP of positive and negative controls None of the three genes tested were methylated in eight normal bone marrow samples, (Fig. 1) and 12 normal peripheral blood samples. The positive and negative controls showed the expected MSP results (normal DNA: U-MSP positive/M-MSP negative; methylated DNA: U-MSP negative / M-MSP positive).

MSP in primary CLL marrow samples DAP kinase was methylated in $18(36 \%)$ patients while $p 14$ and Apaf-1 were completely unmethylated in all the primary marrow samples.(Fig. 1)

Statistical analysis

There was no association between $D A P$ kinase methylation and age $(P=0.11)$, sex $(P=0.46)$, Rai stage at diagnosis $(P=0.52)$, poor-risk karyotype (0.73) and lymphocyte count at diagnosis $(P=0.53)$. (Table 2) Median OS for the whole group was 96 months. Projected 5-year OS in patients with limited (Rai stage $\leq 2$ ) and advanced (Rai stage $>2$ ) disease were 72 and $39 \%(P=0.01)$. Patients with and without $D A P$ kinase methylation were 59 and 57\% $(P=0.91)$ (Fig. 2).

Table 1 Methylation-specific polymerase chain reaction (MSP): primer sequences and reaction conditions

\begin{tabular}{|c|c|c|c|c|}
\hline Gene & Forward primer $\left(5^{\prime}-3^{\prime}\right)$ & Reverse primer $\left(5^{\prime}-3^{\prime}\right)$ & Tm/cycles & Reference \\
\hline \multicolumn{5}{|l|}{$D A P$ kinase } \\
\hline M-MSP & GGATAGTCGGATCGAGTTAACGTC & CCCTCCCAAACGCCGA & $63^{\circ} \mathrm{C} / 35$ & $\begin{array}{l}\text { Chan } \\
\text { et al. } 2002\end{array}$ \\
\hline U-MSP & $\begin{array}{l}\text { GGAGGATAGTTGGATTGAG } \\
\text { TTAATGTT }\end{array}$ & САААТСССТСССАААСАССАА & - & - \\
\hline \multicolumn{5}{|c|}{ - } \\
\hline M-MSP & GTGTTAAAGGGCGGCGTAGC & AAAACCCTCACTCGCGACGA & $65^{\circ} \mathrm{C} / 35$ & $\begin{array}{l}\text { Esteller } \\
\text { et al. } 2000\end{array}$ \\
\hline U-MSP & $\begin{array}{l}\text { TTTTTGGTGTTAAAGGGT } \\
\text { GGTGTAGT }\end{array}$ & САСАААААСССТСАСТСАСААСАА & - & - \\
\hline \multicolumn{5}{|c|}{ ( } \\
\hline M-MSP* & TATTGCGATATTGTTTTAAATTCGA & GAAACGTAACTAAACCTCAAAAACG & $64^{\circ} \mathrm{C} / 35$ & Genebank \\
\hline U-MSP** & TATTGTGATATTGTTTTAAATTTGA & $\begin{array}{l}\text { CAAAACATAACTAAACCTC } \\
\text { AAAAACAC }\end{array}$ & - & AB070829 \\
\hline
\end{tabular}

$T m$ annealing temperature, $M-M S P$ methylation-specific polymerase chain reaction for the methylated allele, $U$ - $M S P$ MSP for the unmethylated allele, Primers for Apaf-1: $M-M S P^{*}$ nucleotides 785-809, U-MSP** nucleotides $938-963$ in Genbank accession number AB070829 
$\mathbf{A}$

DAPK U-MSP

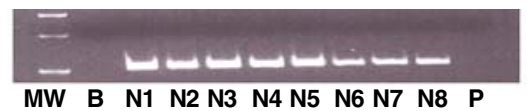

DAPK M-MSP

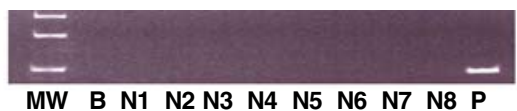

MW B N1 N2 N3 N4 N5 N6 N7 N8 P

DAK UM - MSP on CLL samples

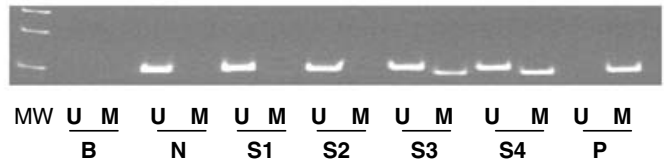

P: positive control $\quad \mathrm{N}$ : normal donor S:CLL sample; B: reagent blank

B

p14 U-MSP

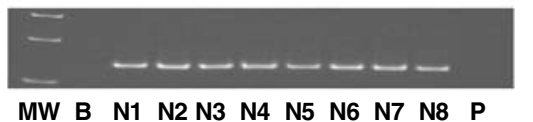

p14 M-MSP

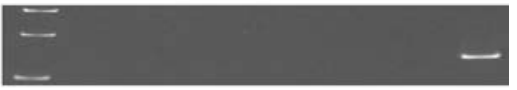

MW B N1 N2 N3 N4 N5 N6 N7 N8 P

p14 UM - MSP on CLL samples

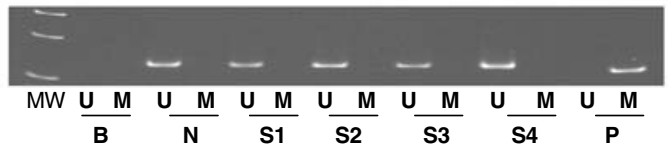

P: positive control N: normal donor S: CLL sample B: reagent blank

C
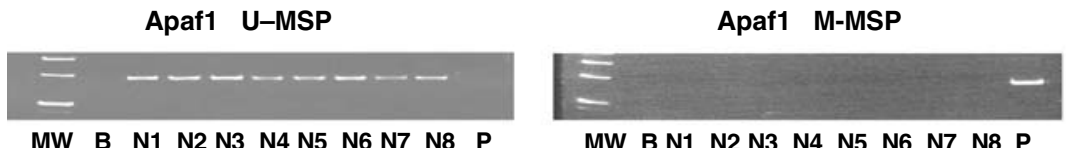

MW B N1 N2 N3 N4 N5 N6 N7 N8 P

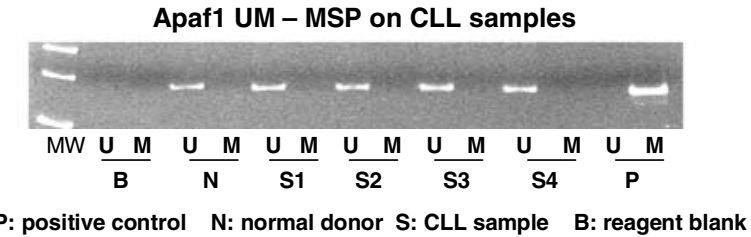

Fig. 1 Hypermethylation of DAP kinase. a DAP kinase methylation. U-MSP showed that the methylated control (M) was totally methylated. All 8 normal controls (N1-N8) showed an amplifiable band. In the M-MSP, the methylated control showed an amplifiable band, but none of the normal controls showed amplification. For the CLL samples, S3 and S4 showed DAP kinase hypermethylation. $B$ reagent blank, $P$ methylated positive control, $M W$ molecular weight control, $N 1-N 8$ normal marrow DNA, S1-S4 primary CLL samples. b $p 14$ hypermethylation UMSP showed that the methylated control (M) was totally methylated. All 8 normal controls (N1-N8) showed an amplifiable band. In the M-MSP, the methylated control showed an amplifiable band, but none of the normal controls showed amplification. For the CLL samples, none showed p14 hypermethylation. $B$ reagent blank, $P$ methylated positive control, $M W$ molecular weight control, N1-N8 normal marrow DNA, S1-S4 primary CLL samples. c Apaf-1 hypermethylation. U-MSP showed that the methylated control (M) was totally methylated. All 8 normal controls (N1-N8) showed an amplifiable band. In the M-MSP, the methylated control showed an amplifiable band, but none of the normal controls showed amplification. For the CLL samples, none showed Apaf- 1 hypermethylation. $B$ reagent blank, $P$ methylated positive control, $M W$ molecular weight control, N1-N8 normal marrow DNA, S1-S4 primary CLL samples

Moreover, similar to Caucasian patients, advanced Rai stage disease conferred an inferior OS. Therefore, our series represented CLL patients similar to Caucasian patients.

Ideally, MSP status of the neoplastic lymphocytes is best studied if marrow cells have been sorted for CD5 
Table 2 Association of DAP kinase hypermethylation with patients' characteristics

\begin{tabular}{llll}
\hline DAP kinase & Methylated & Unmethylated & $P$ value \\
\hline Number & $18(36 \%)$ & $32(64 \%)$ & - \\
Median age & 68 & 62 & 0.11 \\
Sex & & & \\
$\quad$ Male & 13 & 27 & 0.46 \\
Female & 5 & 5 & - \\
Median lymphocyte count & 51.1 & 39.1 & 0.52 \\
Rai stage & & & \\
$\quad \leq$ II & 9 & 20 & 0.53 \\
$>$ II & 9 & 12 & - \\
Poor-risk karyotype* & & & \\
No & 6 & 16 & 0.73 \\
Yes & 5 & 10 & - \\
\hline
\end{tabular}

*Karyotype and DAP kinase hypermethylation data available in $37 / 50$ patients

and CD23 dually positive cells. Here, MSP of the genes has been validated in normal control DNA by demonstration of the lack of methylation in normal controls, and thus M-MSP amplification is specific to tumor cells. Given that methylation detected by MSP is a positive signal with a high sensitivity (as evidenced by serial dilution of positive methylated control DNA: 1 in $10^{3}$ for $R A R \alpha$, (Chim et al. 2005b) 1 in $10^{4}$ for $p 16$ and $p 73$, (Chim et al. 2001a, 2004b) and 1 in $10^{5}$ for $p 15$ gene, (Chim et al. 2001b) our results are still valid without sorting of the marrow for lymphocytes, given that the marrow in these patients had leukemic infiltration ranging from 37 to $90 \%$ (median: $65 \%)$.(Materials and method) On the other hand, the presence of U-MSP amplification was likely due to the invariable contamination of the marrow by unmethylated normal cells. Moreover, the lack of tumor cell selection or enrichment precludes assessment of important information such as the level of DAP kinase methylation and expression of DAP kinase in primary samples. If there is no intratumoral heterogeneity, the level of methylation such as mono- or bi-allelic methylation might have been studied by quantitative MSP, and the level of DAP expression by RT-PCR or Western hybridization).

We showed frequent hypermethylation of $D A P$ kinase but not p14 and Apaf1 in CLL, consistent with the pathogenesis involving resistance to apoptosis in CLL cells. Moreover, frequent DAP kinase methylation has also been demonstrated in B-cell lymphoma but not myeloid or T-cell malignancies, and thus might be important in carcinogenesis of B-cell malignancies. (Katzenellenbogen et al. 1999)

p14 hypermethylation has been extensively studied in solid cancers, and has been shown to be modestly
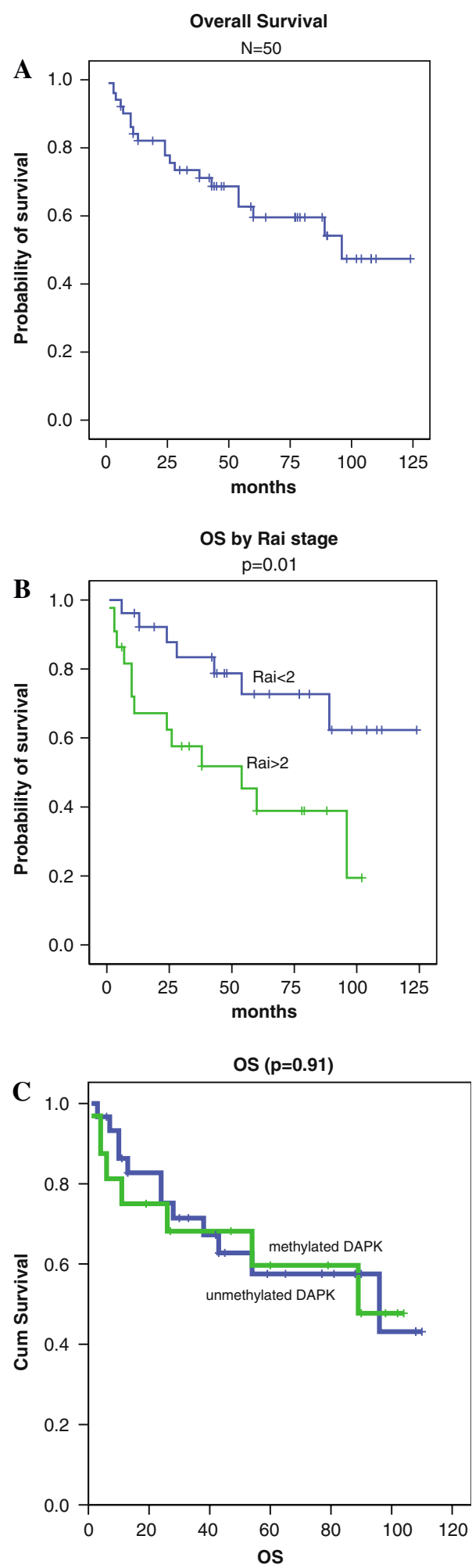

Fig. 2 Overall survival. a OS of all CLL patients. Median OS was 96 months. b Advanced Rai stage was associated with an inferior OS. Projected 5-year OS of CLL patients with limited and advanced Rai stage disease were 72 and $39 \%, P=0.01$. c There was no difference in the OS of patients with and without $D A P$ kinase hypermethylation 
methylated $(10-30 \%)$ in renal, gastric and colorectal cancers. (Estellet et al. 2001) In haematological cancers, apart from accelerated phase of CML, where $40 \%$ of patients carried p14 methylation, (Nagy et al. 2003) p14 hypermethylation is uncommon, and has been reported in only $8 \%$ of ALL, (Romen-Gomez et al. 2004) but not t-MDS/AML $(N=81)$. (Christiansen et al. 2003) We demonstrated the absence of p14 hypermethylation in CLL, consistent with detection of p14 expression in the tumor cells of CLL patients. (Taniguchi et al. 1999) Previous studies have reported the absence of $p 14 / p 16$ gene deletion in CLL, (Drexler et al. 1998) together with our data of absence of p14 methylation of p14 in CLL, p14 does not appear to be targeted in the dysregulation of the DAP kinase/ p14/HDM2/p53/Apaf-1 apoptosis pathway.

Hypermethylation of Apaf-1 has been detected in melanoma, (Soengas et al. 2001) and recently in acute leukaemia. (Roman-Gomez et al. 2004) As yet, there is no data on Apaf-1 methylation in CLL, and our study is the first report of the absence of Apaf-1 hypermethylation in CLL, consistent with the finding of Apaf-1 protein expression in CLL. (Winkler et al. 2005)

In summary, DAP kinase but not p14 or Apaf-1 is frequently targeted by methylation, suggesting an important role of DAP kinase dysregulation in the DAP kinase/p14/HDM2/p53/Apaf-1 apoptosis pathway. The clinical behavior of CLL in Orientals is similar to Caucasian CLL patients.

Acknowledgment We thank Professor LC Chan and Dr Clarence Lam in the University Department of Pathology, Queen Mary Hospital, for pathological diagnoses, and Miss YY Chan and her team for the provision of excellent nursing care.

\section{Reference}

Chan EC, Lam SY, Tsang KW, Lam B, Ho JC, Fu KH, Lam WK, Kwong YL (2002) Aberrant promoter methylation in Chinese patients with non-small cell lung cancer: patterns in primary tumors and potential diagnostic application in bronchoalevolar lavage. Clin Cancer Res 8:3741-3746

Chim CS, Tam CY, Liang R, Kwong YL (2001a) Methylation of p15 and p16 genes in adult acute leukemia: lack of prognostic significance. Cancer 91:2222-2229

Chim CS, Liang R, Tam C, Kwong YL (2001b) p15 and P16 promoter methylation in acute promyelocytic leukemia. J Clin Oncol 19:2033-2040

Chim CS, Liang R, Kwong YL (2002) Gene promoter hypermethylation in hematologic malignancies. Hematol Oncol 20: $167-176$

Chim CS, Fung TK, Cheung J, Liang R Kwong YL (2004a) SOCS1 and SHP1 hypermethylation in multiple myeloma: implications for epigenetic activation of the Jak/STAT pathway. Blood 103:4630-4635
Chim CS, Kwong YL, Fung TK, Liang R (2004b) Methylation profiling in multiple myeloma. Leuk Res 28:379-385

Chim CS, Fung TK, Wong KF, Lau JS, Law M, Liang R (2005a) Methylation of INK4 and CIP/KIP families of cyclindependent kinase inhibitor (CKI) in chronic lymphocytic leukemia (CLL) in Chinese. J Clin Pathol (in press)

Chim CS, Wong AS, Pang A, Chu P, Lau JS, Wong KF, Kwong YL (2005b) Aberrant promoter methylation of the retinoic acid receptor alpha gene in acute promyelocytic leukemia. Leukemia (in press)

Chim CS, Fung TK, Wong KF, Lau JS, Liang R (2006) Infrequent Wnt inhibitory factor-1 (Wif-1) methylation in Chronic Lymphocytic Leukemia. Leukemia Res (in press)

Christiansen DH, Andersen MK, Pedersen-Bjergaard J (2003) Methylation of p15INK4B is common, is associated with deletion of genes on chromosome arm $7 \mathrm{q}$ and predicts a poor prognosis in therapy-related myelodysplasia and acute myeloid leukemia. Leukemia 17:1813-1819

Drexler HG (1998) Review of alterations of the cyclin-dependent kinase inhibitor INK4 family genes p15, p16, p18 and p19 in human leuKemia-lymphoma cells. Leukemia 12:845-859

Esteller M, Tortola S, Toyota M, Capella G, Peinado MA, Baylin SB, Herman JG (2000) Hypermethylation-associated inactivation of p14(ARF) is independent of p16(INK4a) methylation and p53 mutational status. Cancer Res 60:129133

Esteller M, Corn PG, Baylin SB, Herman JG (2001) A gene hypermethylation profile of human cancers. Can Res 61: 3225-3229

Hengartner MO (2000) The biochemistry of apoptosis. Nature 407:770-6

Herman JG, Baylin SB (2003) Gene silencing in cancer in association with promoter hypermethylation. N Engl J Med 349:2042-2054

Juliusson G, Merup M (1998) Cytogenetics in chronic lymphocytic leukemia. Semin Oncol 25:19-26

Katzenellenbogen RA, Baylin SB, Herman JG (1999) Hypermethylation of the DAP-kinase $\mathrm{CpG}$ island is a common alteration in B-cell malignancies. Blood 93:4347-4353

Keating MJ, Chiorazzi N, Messmer B, Damle RN, Allen SL, Rai KR, Ferrarini M, Kipps TJ (2003) Biology and treatment of chronic lymphocytic leukemia. In Hematology (Am Soc Hematol Educ Program). pp 153-175

Kwong YL, Wong KF, Chan LC, Liang RHS, Chan JKC, Wei D, Chiu EKW, Chan CH, Todd D, Chan TK (1994) The spectrum of chronic lymphoproliferative disorders in Chinese people: an analysis of 64 cases. Cancer 74:174-181

Lowe SW, Cepero E, Evan G (2004) Intrinsic tumour suppression. Nature 432:307-315

Ma SY, Au WY, Chim CS, Lie AK, Lam CC, Tse E, Leung AY, Liang R, Kwong YL (2004) Fludarabine, mitoxantrone and dexamethasone in the treatment of indolent $\mathrm{B}$ - and T-cell lymphoid malignancies in Chinese patients. Br J Haematol 124:754-761

Muller-Hermelink HK, Catovsky D, Monstserrat E, Harris NL (2001) Chronic lymphocytic leukemia/small lymphocytic lymphoma. In: Jaffe ES, Harris NL, Stein H, Vardiman JW (eds) Pathology and genetics of tumours of the haematopoietic and lymphoid tissues world health organization classification of tumours, International Agency for Research on Cancer, Lyon pp 127-130

Nagy E, Beck Z, Kiss A, Csoma E, Telek B, Konya J, Olah E, Rak K, Toth FD (2003) Frequent methylation of p16INK4A and p14ARF genes implicated in the evolution of chronic myeloid leukaemia from its chronic to accelerated phase. Eur J Cancer 39:2298-2305 
Parker SL, Tong T, Bolden S, Wingo PA (1997) Cancer statistics. Ca Cancer J Clin 47:5-27

Peller S, Rotter V (2003) TP53 in hematological cancer: low incidence of mutations with significant clinical relevance. Hum Mutat 21:277-284

Raveh T, Droguett G, Horwitz MS, DePinho RA, Kimchi A (2001) DAP kinase activates a p19ARF/p53-mediated apoptotic checkpoint to suppress oncogenic transformation. Nat Cell Biol 3:1-7

Roman-Gomez J, Jimenez-Velasco A, Castillejo JA, Agirre X, Barrios M, Navarro G, Molina FJ, Calasanz MJ, Prosper F, Heiniger A, Torres A (2004) Promoter hypermethylation of cancer-related genes: a strong independent prognostic factor in acute lymphoblastic leukemia. Blood 104:2492-2498

Sherr CJ (2001) The INK4a/ARF network in tumour suppression. Nat Rev Mol Cell Biol 2:731-737
Soengas MS, Capodieci P, Polsky D, Mora J, Esteller M, OpitzAraya X, McCombie R, Herman JG, Gerald WL, Lazebnik YA, Cordon-Cardo C, Lowe SW (2001) Inactivation of the apoptosis effector Apaf-1 in malignant melanoma. Nature 409:207-211

Taniguchi T, Chikatsu N, Takahashi S, Fujita A, Uchimaru K, Asano S, Fujita T, Motokura T (1999) Expression of p16INK4A and p14ARF in hematological malignancies. Leukemia 13:1760-1769

Winkler D, Schneider C, Kröber A, Pasqualucci L, Lichter P, Döhner H, Stilgenbauer S (2005) Protein expression analysis of chromosome 12 candidate genes in chronic lymphocytic leukemia (CLL). Leukemia 19:1211-1215

Wong KF, Chan JKC (1999) Cytogenetic abnormalities in chronic B-cell lymphoproliferative disorders in Chinese. Cancer Genet Cytogenet 111:55-60 